\title{
A Novel Kinetic Spectrophotometric Method for the Determination of Dopamine in Biological and Pharmaceutical Samples
}

\author{
M. Reza Shishehbore, Adel Asgharpoor, and N. Nasirizadeh \\ Department of Chemistry, Yazd Branch, Islamic Azad University, Yazd 8916871967, Iran \\ Correspondence should be addressed to M. Reza Shishehbore; shishehbor47@gmail.com
}

Received 31 May 2013; Accepted 31 July 2013

Academic Editor: Pranav S. Shrivastav

Copyright (C) 2013 M. Reza Shishehbore et al. This is an open access article distributed under the Creative Commons Attribution License, which permits unrestricted use, distribution, and reproduction in any medium, provided the original work is properly cited.

\begin{abstract}
A sensitive and accurate method for quantitative determination of dopamine was introduced. The proposed method is based on inhibitory effect of dopamine on the oxidation of thionine by bromate in acidic media. The change in absorbance was followed spectrophotometrically at $601 \mathrm{~nm}$. The dependence of sensitivity on the reaction variables was investigated and optimized to obtain the maximum sensitivity. Under optimum experimental conditions, calibration curve was linear over the range $0.2-103.3 \mu \mathrm{g} \mathrm{mL}{ }^{-1}$ of dopamine. The relative standard deviations $(n=6)$ of $0.5,1.0,5.0$, and $30.0 \mu \mathrm{g} \mathrm{mL}^{-1}$ of dopamine were $1.13,1.02,0.99$, and $0.97 \%$, respectively. The limit of detection was $0.057 \mu \mathrm{g} \mathrm{mL} \mathrm{m}^{-1}$ of dopamine. The effect of diverse species was also investigated. The developed method was successfully applied for the determination of dopamine in pharmaceutical and biological samples.
\end{abstract}

\section{Introduction}

Dopamine, an organic chemical compound in the catecholamine family, was first synthesized in 1910 in England. The function of dopamine that resulted in awarding the 2000 noble prize in physiology or medicine was investigated by Swedish Clarsson. It was shown that dopamine is not only a precursor of epinephrine and norepinephrine but also a neurotransmitter. Dopamine, produced in several areas of the brain, has an important role in the brain system that is responsible for reward-driven learning and feeling pleasure $[1,2]$. Parkinson's and schizophrenia were caused by decreasing and increasing of dopamine level, respectively. Moreover, the level of dopamine is increased by giving addictive drugs such as cocaine and methamphetamine $[3,4]$. Thus, developing a reliable method for quantitative determination of dopamine in biological fluids has a great importance for analytical and clinical aims.

In view of the great importance of dopamine, numerous analytical techniques have been documented for its determination in different matrices and at different levels. The most common method is chromatography including high performance liquid chromatography [5-7], high performance liquid chromatography-mass spectrometry [8], and electrokinetic chromatography [9]. The method was mainly used in the analysis of dopamine and dopamine metabolites in biological fluids. Shortages such as set-up cost and hard operation were found in their application. Electroanalytical chemists have shown great interest in this field, and various modified electrodes using nanoparticles [10, 11], polymer films $[12,13]$, ionic liquid $[14,15]$, and other modifiers [1618] have been constructed. The main drawback of electrochemical methods is poor selectivity of the measurement. Therefore, the major target of electroanalytical methods for increasing the selectivity is the use of modifier for reducing the oxidation potential to less positive potentials especially in the case of complex matrices. Moreover, low precision (relatively high RSD\%) is the other disadvantage of the electrochemical methods.

Catalytic spectrophotometric method as a relatively low cost and easy handling technique with sufficient accuracy is considered one of the most effective and appropriate methods for routine analysis of foods [19, 20], chemical [21], pharmaceutical, and biological $[22,23]$ samples. To the best 
of our knowledge, only a document based on catalytic effect of dopamine [24] has been found for the determination of it. Analytical parameters of the method in comparison to the developed method have been summarized in Table 1.

The present paper reports a simple, rapid, and selective kinetic spectrophotometric method for the determination of dopamine at $601 \mathrm{~nm}$, via thionine-bromate system. This method was applied, with good results, to the routine determination of dopamine in pharmaceutical preparations, serum and urine samples.

\section{Experimental}

2.1. Chemicals and Reagents. All chemicals used were of analytical reagent grade and were used without further purification. Doubly distilled water was used throughout the experiments. $50 \mathrm{~mL}$ standard working dopamine solution of $100.0 \mathrm{mg} \mathrm{L}^{-1}$ was prepared by dissolving $0.0062 \mathrm{~g}$ of dopamine hydrochloride ( $>99 \%$, Sigma) in water daily. Thionine solution (approximately, 90\%, $3.0 \times 10^{-4} \mathrm{~mol} \mathrm{~L}^{-1}$ ) was prepared by dissolving $0.0862 \mathrm{~g}$ of thionine (Merck) in appropriate amount of water and diluted to $1000 \mathrm{~mL}$ in a volumetric flask. Potassium bromate stock solution of $0.05 \mathrm{~mol} \mathrm{~L}^{-1}$ was prepared by dissolving $4.1752 \mathrm{~g}$ of $\mathrm{KBrO}_{3}$ ( $\geq 99.8 \%$, Merck) in $500 \mathrm{~mL}$ volumetric flask. Sulfuric acid solution $4.0 \mathrm{~mol} \mathrm{~L}^{-1}$ was prepared by appropriate dilution of concentrated sulfuric acid solution in water.

Dopamine injection solution $(200 \mathrm{mg} / 5.0 \mathrm{~mL})$ was produced from Iranian Pharmaceutical Co.

2.2. Apparatus. A double beam UV-vis spectrophotometer Shimadzu (160-A, Japan) with $1 \mathrm{~cm}$ matched glass cell was used for recording absorption spectra and absorbance measurements. All solutions were kept in a thermostatic water bath at $25.0 \pm 0.1^{\circ} \mathrm{C}$. A stop watch was used for recording the reaction time.

2.3. Recommended Procedure. After initial kinetic spectrophotometric studies of the reaction system, the reagent concentrations (except the dopamine) were judiciously chosen for the analytical procedure. For this purpose, thermal equilibrium was established at $25.0 \pm 0.1^{\circ} \mathrm{C}$ for $30 \mathrm{~min}$ in thermostated water bath. Then, to a $10 \mathrm{~mL}$ volumetric flask, $1.1 \mathrm{~mL}$ of $4.0 \mathrm{~mol} \mathrm{~L}^{-1}$ of sulfuric acid, $0.9 \mathrm{~mL}$ of $3.0 \times$ $10^{-4} \mathrm{~mol} \mathrm{~L}^{-1}$ of thionine solution, and $0.3 \mathrm{~mL}$ of $100 \mu \mathrm{g} \mathrm{mL}^{-1}$ of dopamine solution were placed. The solution was diluted to $8 \mathrm{~mL}$ approximately. Then, $0.1 \mathrm{~mL}$ of $0.05 \mathrm{~mol} \mathrm{~L}^{-1}$ bromate solution was added to the reaction mixture, followed by dilution to $10 \mathrm{~mL}$ with water. Time measurement was just started after adding the last drop of bromate solution. After thorough mixing, a portion of the solution was transferred to the cell and the absorbance was measured against water at $601 \mathrm{~nm}$ and $25^{\circ} \mathrm{C}$ for fixed times of 0.5 and $4.5 \mathrm{~min}$. The measurements were repeated in the absence of dopamine to obtain the value for the uninhibited reaction as the absorbance of the blank. The absorbance changes of the inhibited and uninhibited reactions were labeled $\Delta A_{s}$ and $\Delta A_{b}$, respectively. The difference in the absorbance
$\left(\Delta A=\Delta A_{b}-\Delta A_{s}\right)$ was considered as the response. Under optimum experimental conditions, a calibration curve was constructed by plotting the response $(\Delta A)$ against dopamine concentration.

2.4. Procedure of Sample Preparation. The injection solution (200 mg) was diluted in a $1 \mathrm{~L}$ volumetric flask. An appropriate amount of the solution was used in each analysis. Human urine and serum were used as biological samples for the determination of dopamine. At first, each sample was spiked with different amounts of dopamine (including two linear segments of calibration curve), and $\mathrm{C}_{18}$ cartridge (Supelco Inc., $10 \mathrm{~mL}$ ) was used for purification and preconcentration of dopamine as described previously [26].

\section{Results and Discussion}

Thionine (also known as Lauth's violet), a dark green crystalline powder thiazine base, is useful as a basic stain in histology for mucin and chromatin because of its metachromatic properties. Oxidation of thionine by strong oxidizing agents resulted in the formation of a colorless product. It was used for kinetic spectrophotometric studies of hydrazine [21], vanadium [25], and ruthenium [27].

The aim of this study is to establish a new strategy for quantitative determination of dopamine. The method is based on the inhibitory effect of dopamine on the oxidation of thionine by bromate in acidic media. The possible mechanism is described as follow.

(1) Thionine in reduced form is oxidized by bromate in acidic media that resulted to production of bromide and thionine in reduced form as a colorless product. The reaction was quite slow (reaction (1)):

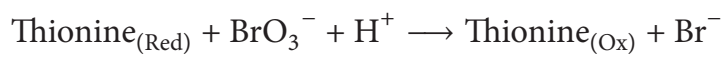

(2) Bromine generation is down by a well known reaction between bromide and bromate in acidic media (reaction (2)):

$$
\mathrm{BrO}_{3}{ }^{-}+\mathrm{H}^{+}+\mathrm{Br}^{-} \longrightarrow \mathrm{Br}_{2}+\mathrm{H}_{2} \mathrm{O}
$$

(3) Oxidation of thionine is down by generated bromine that is faster than oxidation by bromate (reaction (3)):

Thionine $_{(\mathrm{Red})}+\mathrm{Br}_{2}+\mathrm{H}^{+} \longrightarrow$ Thionine $_{(\mathrm{Ox})}+\mathrm{Br}^{-}$

(4) A reducing agent (in this case dopamine) reacts rapidly with bromine and therefore inhibits the decolorizing reaction of thionine (reaction (4)):

Dopamine $_{(\mathrm{Red})}+\mathrm{Br}_{2}+\mathrm{H}^{+} \longrightarrow \mathrm{Br}^{-}+$Dopamine $_{(\mathrm{Ox})}$

Since the level of inhibition depends on the dopamine amount, developing an analytical method for the determination of it is possible. 
TABLE 1: Comparison of some analytical characteristic of reported catalytic spectrophotometric method to the proposed method for the determination of dopamine.

\begin{tabular}{lcccccc}
\hline Reaction system & Effect on reaction system & Method & LDR $\left(\mu \mathrm{g} \mathrm{mL}{ }^{-1}\right)$ & DL $\left(\mu \mathrm{g} \mathrm{mL}^{-1}\right)$ & Real sample & Reference \\
\hline $\mathrm{Mo}(\mathrm{VI})-\mathrm{H}_{2} \mathrm{O}_{2}$ & Catalytic & Tangent & $0.76-6.83$ & $\mathrm{NA}^{\mathrm{a}}$ & Rat brain \\
Thionine- $\mathrm{BrO}_{3}{ }^{-}$ & Inhibitory & Fixed time & $0.2-103.3$ & 0.057 & Urine, serum, and pharmaceutical & This work \\
\hline
\end{tabular}

${ }^{\mathrm{a}}$ Not available.

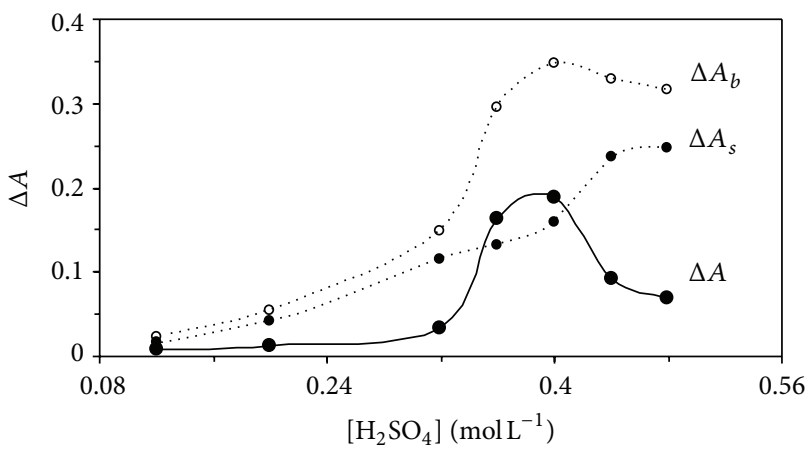

FIGURE 1: Effect of sulfuric acid concentration on the rate of uninhibited $\left(\Delta A_{b}\right)$ and inhibited $\left(\Delta A_{s}\right)$ reactions and response $(\Delta A)$. (Conditions: sulfuric acid, $0.12-0.48 \mathrm{~mol} \mathrm{~L}^{-1}$; thionine, $27.0 \mu \mathrm{mol} \mathrm{L}^{-1}$; dopamine, $3.0 \mu \mathrm{g} \mathrm{mL}^{-1}$; bromate, $0.5 \mathrm{mmol} \mathrm{L}^{-1} ; 25^{\circ} \mathrm{C}$ and $270 \mathrm{~s}$.)

To take maximum sensitivity of the proposed procedure, the reagents concentration and reaction conditions must be optimized. The parameters were optimized by one at a time method. The maximum difference between blank and sample signal $(\Delta A)$ was considered to obtain the most sensitive results.

\subsection{Optimization of Effective Parameters on the Reaction Rate.} The influence of sulfuric acid concentration on the response was studied over the range of 0.12 to $0.48 \mathrm{~mol} \mathrm{~L}^{-1}$. As it can be seen in Figure 1, the response was increased along with the sulfuric acid concentration up to $0.4 \mathrm{~mol} \mathrm{~L}^{-1}$. Therefore, $0.4 \mathrm{~mol} \mathrm{~L}^{-1}$ of sulfuric acid concentration was selected as optimum. The decrease of response at higher acidic media may be attributed to protonation of thionine.

Figure 2 shows the influence of thionine concentration on the inhibited and uninhibited reactions over the range of 15.0 to $45.0 \mu \mathrm{mol} \mathrm{L}{ }^{-1}$. As it can be seen, the response was increased up to $30.0 \mu \mathrm{mol} \mathrm{L}^{-1}$ whereas at higher concentrations it was decreased. Therefore, $30.0 \mu \mathrm{mol} \mathrm{L}^{-1}$ of thionine was selected for further study. Aggregation of thionine at higher concentrations can be resulted to this behavior.

Under optimum concentration of sulfuric acid and thionine, the influence of bromate concentration on the sensitivity was investigated in the range of 0.25 to $0.55 \mathrm{mmol} \mathrm{L}^{-1}$. As shown in Figure 3, the maximum sensitivity was obtained at $0.55 \mathrm{mmol} \mathrm{L}^{-1}$. Since the absorbance change of uninhibited is more than inhibited reaction, the sensitivity was decreased.

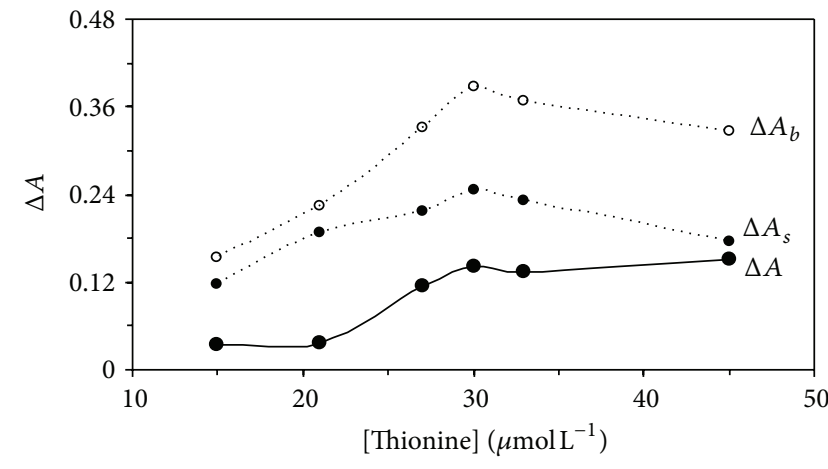

FIGURE 2: Effect of thionine concentration on the rate of uninhibited $\left(\Delta A_{b}\right)$ and inhibited $\left(\Delta A_{s}\right)$ reactions and response $(\Delta A)$. (Conditions: sulfuric acid, $0.40 \mathrm{mmol} \mathrm{L}^{-1}$; thionine, $15.0-45.0 \mu \mathrm{mol} \mathrm{L}^{-1}$; dopamine, $3.0 \mu \mathrm{g} \mathrm{mL}^{-1}$; bromate, $0.5 \mathrm{mmol} \mathrm{L}^{-1} ; 25^{\circ} \mathrm{C}$ and $270 \mathrm{~s}$.)

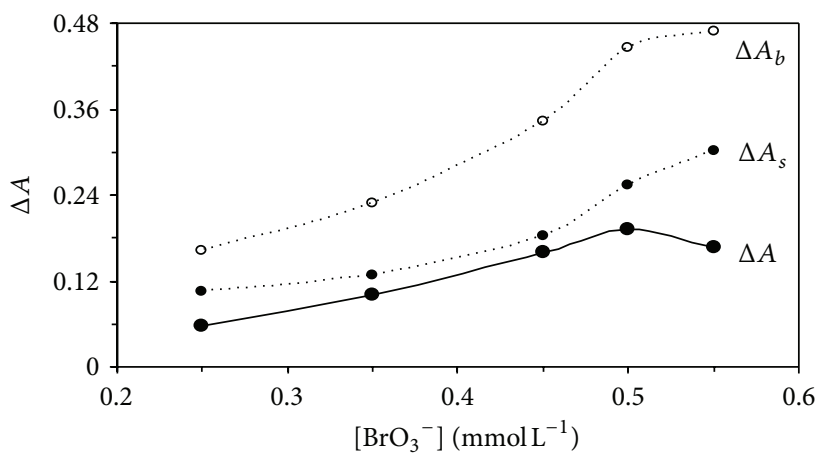

FIGURE 3: Effect of bromate concentration on the rate of uninhibited $\left(\Delta A_{b}\right)$ and inhibited $\left(\Delta A_{s}\right)$ reactions and response $(\Delta A)$. (Conditions: sulfuric acid, $0.40 \mathrm{mmol} \mathrm{L}^{-1}$; thionine, $30.0 \mu \mathrm{mol} \mathrm{L}^{-1}$; dopamine, $3.0 \mu \mathrm{g} \mathrm{mL}^{-1}$; bromate, $0.25-0.55 \mathrm{mmol} \mathrm{L}^{-1} ; 25^{\circ} \mathrm{C}$ and 270 s.)

The effect of temperature on the reaction rate was studied in the range of 15 to $45^{\circ} \mathrm{C}$ with obtained optimum conditions. The results in Figure 4 show a maximum at $30^{\circ} \mathrm{C}$. Therefore, $30^{\circ} \mathrm{C}$ was selected as the optimum temperature.

The optimum time was found by measuring the change in the absorbance during 30 to $420 \mathrm{~s}$ (Figure 5). The reaction rate was increased up to $240.0 \mathrm{~s}$, and for longer times it was decreased. Therefore, $240 \mathrm{~s}$ was selected as the optimum value. 


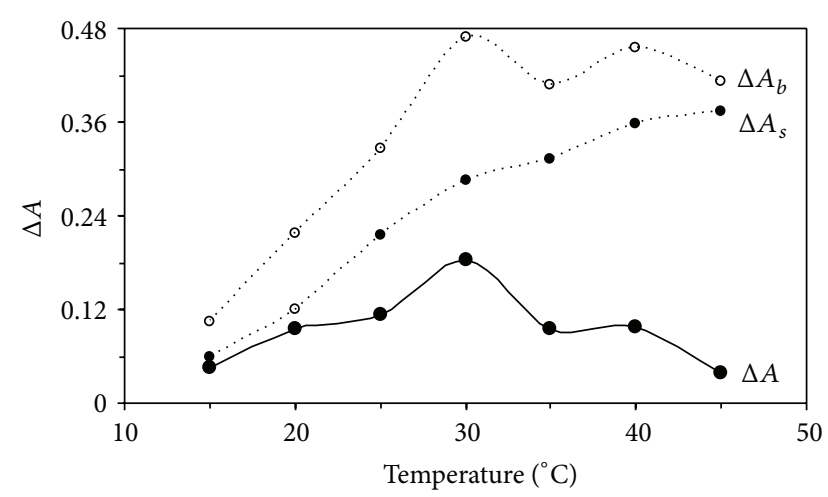

Figure 4: Effect of temperature on the rate of uninhibited $\left(\Delta A_{b}\right)$ and inhibited $\left(\Delta A_{s}\right)$ reactions and response $(\Delta A)$. (Conditions: sulfuric acid, $0.40 \mathrm{mmol} \mathrm{L}^{-1}$; thionine, $30.0 \mu \mathrm{mol} \mathrm{L}{ }^{-1}$; dopamine, $3.0 \mu \mathrm{g} \mathrm{mL}^{-1}$; bromate, $0.50 \mathrm{mmol} \mathrm{L}^{-1} ; 15-45^{\circ} \mathrm{C}$ and $270 \mathrm{~s}$.)

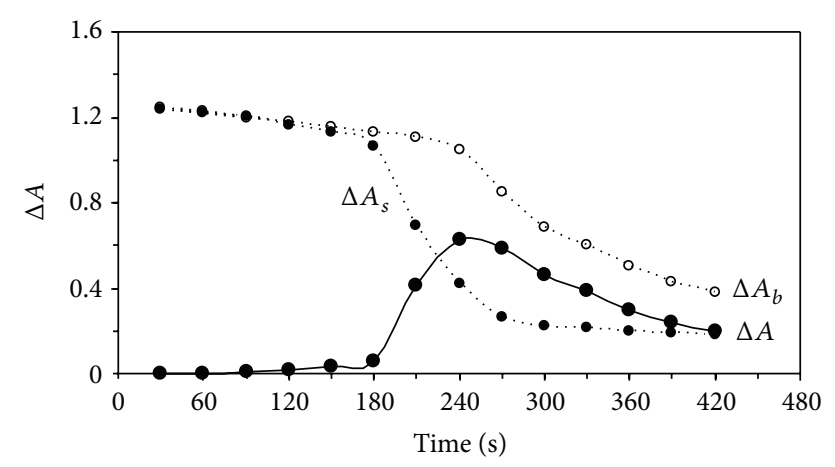

FIGURE 5: Effect of time on the rate of uninhibited $\left(\Delta A_{b}\right)$ and inhibited $\left(\Delta A_{s}\right)$ reactions and response $(\Delta A)$. (Conditions: sulfuric acid, $0.40 \mathrm{mmol} \mathrm{L}^{-1}$; thionine, $30.0 \mu \mathrm{mol} \mathrm{L}^{-1}$; dopamine, $3.0 \mu \mathrm{g} \mathrm{mL}^{-1}$; bromate, $0.50 \mathrm{mmol} \mathrm{L}^{-1} ; 30^{\circ} \mathrm{C}$ and $30-420 \mathrm{~s}$.)

3.2. Analytical Performance. Under optimum experimental conditions, calibration curve was linear over the range $0.2-$ $103.3 \mu \mathrm{g} \mathrm{mL}^{-1}$ of dopamine with two linear segments including $0.2-38.1$ and $38.1-103.3 \mu \mathrm{g} \mathrm{mL}^{-1}$. The regression equations of first and second linear segments as (5) and (6) are as follow:

$$
\begin{aligned}
& \Delta A=0.0175 \text { [dopamine] }+0.1079 \quad\left(R^{2}=0.9992\right), \\
& \Delta A=0.0084 \text { [dopamine] }+0.2433 \quad\left(R^{2}=0.9995\right),
\end{aligned}
$$

where $\Delta A$ is response, [dopamine] is the dopamine concentration in $\mu \mathrm{g} \mathrm{mL}^{-1}$, and $R^{2}$ is the square correlation coefficient. The limit of detection $\left(3 S_{b} / m ; S_{b}\right.$ is the standard deviation of the blank signal for 8 replicate determinations and $m$ is the slope of calibration curve) was $0.057 \mu \mathrm{g} \mathrm{mL}^{-1}$ of dopamine based on (5). The relative standard deviations of six replicate determinations were $1.13,1.02$, and $0.99 \%$ for $0.5,1.0$, and $5.0 \mu \mathrm{g} \mathrm{mL}^{-1}$ of dopamine (in first linear segment)
TABLE 2: Interfering effect of foreign species on the determination of $1.0 \mu \mathrm{g} \mathrm{mL}^{-1}$ of dopamine.

\begin{tabular}{lc}
\hline Foreign species & $\begin{array}{c}\text { Tolerance limit } \\
\left(\mathrm{W}_{\text {Species }} / \mathrm{W}_{\text {dopamine }}\right)\end{array}$ \\
\hline $\mathrm{Li}^{+}, \mathrm{Na}^{+}, \mathrm{Mg}^{+2}, \mathrm{NH}_{4}{ }^{+}$ & 1000 \\
$\mathrm{Ca}^{+2}, \mathrm{~K}^{+}$ & 950 \\
$\mathrm{Cu}^{+2}$ & 700 \\
$\mathrm{Fe}^{+2}$ & 670 \\
$\mathrm{Fe}^{+3}$ & 650 \\
$\mathrm{NO}_{3}{ }^{-}, \mathrm{SO}_{4}{ }^{-2}, \mathrm{CH}_{3} \mathrm{CO}_{2}{ }^{-}, \mathrm{PO}_{4}{ }^{-3}, \mathrm{H}_{2} \mathrm{PO}_{4}{ }^{-}$, & 1000 \\
$\mathrm{CO}_{3}{ }^{-2}$ & 10 \\
$\mathrm{Cl}^{-}, \mathrm{NO}_{2}{ }^{-}$ & 900 \\
$\mathrm{Saccharose}^{-}$ & 850 \\
$\mathrm{Glucose}$ fructose & 800 \\
Ethanol, methanol & 650 \\
Urea & 325 \\
Uric acid & 5 \\
Ascorbic acid & \\
\hline
\end{tabular}

and $0.97 \%$ for $30.0 \mu \mathrm{gL}^{-1}$ of dopamine (in second linear segment), respectively.

3.3. Effect of Diverse Species Study. Selectivity of the developed method was evaluated by studying the effect of foreign species including different ions and coexisting species on the determination of $1.0 \mu \mathrm{g} \mathrm{mL}^{-1}$ dopamine. The tolerance limit was defined as the concentration which gave an error of $3.0 \%$ in the determination of $1.0 \mu \mathrm{g} \mathrm{mL}^{-1}$ of dopamine (about three times the relative standard deviation of the proposed method in $1.0 \mu \mathrm{g} \mathrm{m}^{-1}$ of dopamine). The results are summarized in Table 2.

3.4. Real Sample Analysis. The feasibility of the proposed method for the determination of dopamine in dopamine injection solution as pharmaceutical and human urine and serum sample as biological sample was examined. Pharmaceutical sample preparation was performed using the mentioned procedure. An appropriate amount of the samples were analysed by the recommended procedure, and the results of four replicate determinations were given in Table 3. The obtained results indicated that dopamine contents by the recommended procedure are in good agreement with the labeled value. The statistical $t$-test did not show any significant difference between the results (the 95\% confidence level and three degrees of freedom). Also, the procedure was used for the quantification of dopamine in urine and serum samples. After sample preparation (as discussed previously), the extracted dopamine was analysed using recommended procedure. The results were given in Table 4 . The recoveries vary in the range $99.00-102.13 \%$ and $99.00-101.00 \%$ for urine and serum samples, respectively. Therefore, the developed method is free from interfering effect of matrix effect and suitable for analysis of dopamine in different samples. 
TABLE 3: Determination of dopamine in dopamine injection solution using the developed procedure.

\begin{tabular}{lccccc}
\hline Sample & $\begin{array}{c}\text { Proposed method } \\
\text { Found }^{\mathrm{a}}(\mathrm{mg} / \text { ampoule })\end{array}$ & $\begin{array}{c}\text { RSD } \\
(\%)\end{array}$ & $\begin{array}{c}\text { Labeled } \\
(\mathrm{mg} / \text { ampoule })\end{array}$ & $\begin{array}{c}\text { Statistical test } \\
\text {-test }^{\mathrm{b}}\end{array}$ & $\begin{array}{c}\text { Pharmaceutical } \\
\text { Co./batch no. }\end{array}$ \\
\hline 1 & $199.6 \pm 1.8$ & 0.90 & 200 & 0.44 & 0.35 \\
2 & $200.3 \pm 1.7$ & 0.85 & 200 & 0.33 & Caspian Tamin-Iran/027 \\
1 & $200.3 \pm 1.8$ & 0.90 & 200 & 0.50 & Caspian Tamin-Iran/029 \\
2 & $200.4 \pm 1.6$ & 0.79 & 200 & & \\
\hline
\end{tabular}

${ }^{a}$ Mean \pm standard deviation $(n=4)$.

${ }^{\mathrm{b}}$ Tabulated $t$ value for three degrees of freedom at $P(0.95)$ is 3.18 .

TABLE 4: Determination of dopamine in human urine and serum samples by the developed procedure.

\begin{tabular}{|c|c|c|c|c|}
\hline \multirow{2}{*}{ Sample } & \multicolumn{2}{|c|}{ Proposed method $\left(\mu \mathrm{g} \mathrm{mL}^{-1}\right)$} & \multirow{2}{*}{ RSD (\%) } & \multirow{2}{*}{ Recovery (\%) } \\
\hline & Added & Found & & \\
\hline \multicolumn{5}{|c|}{ Human urine } \\
\hline \multirow{4}{*}{1} & - & $<$ D.L & - & - \\
\hline & 1.0 & $0.99 \pm 0.02$ & 2.02 & 99.00 \\
\hline & 5.0 & $5.04 \pm 0.06$ & 1.19 & 100.80 \\
\hline & 30.0 & $30.64 \pm 0.33$ & 1.08 & 102.13 \\
\hline \multirow{4}{*}{2} & - & $<$ D.L & - & - \\
\hline & 1.0 & $1.02 \pm 0.02$ & 1.12 & 102.00 \\
\hline & 5.0 & $4.96 \pm 0.05$ & 1.04 & 99.20 \\
\hline & 30.0 & $29.71 \pm 0.30$ & 1.00 & 99.03 \\
\hline \multicolumn{5}{|c|}{ Human serum } \\
\hline \multirow{4}{*}{1} & - & $<$ D.L & - & - \\
\hline & 1.0 & $1.01 \pm 0.02$ & 1.98 & 101.00 \\
\hline & 5.0 & $4.97 \pm 0.06$ & 1.21 & 99.40 \\
\hline & 30.0 & $30.52 \pm 0.30$ & 0.98 & 101.73 \\
\hline \multirow{4}{*}{2} & - & $<$ D.L & - & - \\
\hline & 1.0 & $0.99 \pm 0.01$ & 1.01 & 99.00 \\
\hline & 5.0 & $5.03 \pm 0.06$ & 1.19 & 100.60 \\
\hline & 30.0 & $29.88 \pm 0.34$ & 1.13 & 100.40 \\
\hline
\end{tabular}

${ }^{\mathrm{a}}$ Mean \pm standard deviation $(n=4)$.

\section{Conclusion}

Dopamine can be determined with a good precision and accuracy at levels as low as $0.2 \mu \mathrm{g} \mathrm{mL}^{-1}$ using thioninebromate reaction system. The proposed method is simple and more sensitive than the reported method [24]. Furthermore, many shortages such as set-up cost, complex extraction, poor linearity, lack of selectivity, or high limit of detection than other techniques were not found during application.

\section{References}

[1] L. S. Colzato, W. P. M. Van Den Wildenberg, N. C. Van Wouwe, M. M. Pannebakker, and B. Hommel, "Dopamine and inhibitory action control: evidence from spontaneous eye blink rates," Experimental Brain Research, vol. 196, no. 3, pp. 467-474, 2009.

[2] P. S. Goldman-Rakic, S. A. Castner, T. H. Svensson, L. J. Siever, and G. V. Williams, "Targeting the dopamine D1 receptor in schizophrenia: insights for cognitive dysfunction," Psychopharmacology, vol. 174, no. 1, pp. 3-16, 2004.
[3] F. M. Benes, "Carlsson and the discovery of dopamine," Trends in Pharmacological Sciences, vol. 22, no. 1, pp. 46-47, 2001.

[4] P. Calabresi, B. Picconi, A. Tozzi, and M. Di Filippo, "Dopamine-mediated regulation of corticostriatal synaptic plasticity," Trends in Neurosciences, vol. 30, no. 5, pp. 211-219, 2007.

[5] M. Tsunoda, C. Aoyama, H. Nomura, T. Toyoda, N. Matsuki, and T. Funatsu, "Simultaneous determination of dopamine and 3,4-dihydroxyphenylacetic acid in mouse striatum using mixed-mode reversed-phase and cation-exchange high-performance liquid chromatography," Journal of Pharmaceutical and Biomedical Analysis, vol. 51, no. 3, pp. 712-715, 2010.

[6] J. Wen, L. Zhou, L. Jin, X. Cao, and B.-C. Ye, "Overoxidized polypyrrole/multi-walled carbon nanotubes composite modified electrode for in vivo liquid chromatographyelectrochemical detection of dopamine," Journal of Chromatography $B$, vol. 877, no. 20-21, pp. 1793-1798, 2009.

[7] M. Karimi, J. L. Carl, S. Loftin, and J. S. Perlmutter, "Modified high-performance liquid chromatography with electrochemical detection method for plasma measurement of levodopa, 3O-methyldopa, dopamine, carbidopa and 3,4-dihydroxyphenyl 
acetic acid," Journal of Chromatography B, vol. 836, no. 1-2, pp. 120-123, 2006.

[8] K. Syslová, L. Rambousek, M. Kuzma et al., "Monitoring of dopamine and its metabolites in brain microdialysates: method combining freeze-drying with liquid chromatography-tandem mass spectrometry," Journal of Chromatography A, vol. 1218, no. 21, pp. 3382-3391, 2011.

[9] H.-M. Huang and C.-H. Lin, "Methanol plug assisted sweepingmicellar electrokinetic chromatography for the determination of dopamine in urine by violet light emitting diode-induced fluorescence detection," Journal of Chromatography B, vol. 816, no. 1-2, pp. 113-119, 2005.

[10] M. J. Song, S. K. Lee, J. H. Kim, and D. S. Lim, "Dopamine sensor based on a boron-doped diamond electrode modified with a polyaniline/Au nanocomposites in the presence of ascorbic acid," Analytical Sciences, vol. 28, no. 6, pp. 583-587, 2005.

[11] M. P. N. Bui, C. A. Li, K. N. Han, X. H. Pham, and G. H. Seong, "Electrochemical determination of cadmium and lead on pristine single-walled carbon nanotube electrodes," Analytical Sciences, no. 7, pp. 699-704, 2012.

[12] M. He and X. Zheng, "A highly sensitive and selective method for dopamine detection based on poly (folic acid) film modified electrode," Journal of Molecular Liquids, vol. 173, no. 3, pp. 2934, 2012.

[13] M. B. Gholivand and M. Amiri, "Simultaneous detection of dopamine and acetaminophen by modified gold electrode with polypyrrole/aszophloxine film," Journal of Electroanalytical Chemistry, vol. 676, no. 6, pp. 53-59, 2012.

[14] Y. Li, X. Liu, X. Liu et al., "Application of multi-walled carbon nanotubes modified carbon ionic liquid electrode for electrocatalytic oxidation of dopamine," Colloids and Surfaces B, vol. 88, no. 1, pp. 402-406, 2011.

[15] Y. Li, X. Liu, X. Zeng et al., "Selective and sensitive detection of dopamine in the presence of ascorbic acid by molecular sieve/ionic liquids composite electrode," Electrochimica Acta, vol. 56, no. 6, pp. 2730-2734, 2011.

[16] K. Sugawara, A. Yugami, and T. Kadoya, "Voltammetric sensing of phosphoproteins using a gallium(III) acetylacetonatemodified carbon paste electrode," Analytical Sciences, vol. 28, no. 3, pp. 251-255, 2012.

[17] X. Li, M. Chen, and X. Ma, "Selective determination of Epinephrine in the presence of ascorbic acid using a glassy carbon electrode modified with graphene," Analytical Sciences, vol. 28, no. 2, pp. 147-151, 2012.

[18] H. Sakamoto, R. Hatsuda, K. Miyamura, H. Shiraishi, and S. Sugiyama, "Electrochemical selective detection of uric acid using a copper-modified carbon electrode," Analytical Sciences, vol. 27, no. 3, pp. 333-337, 2011.

[19] M. R. Shishehbore, A. Sheibani, and R. Jokar, "Kinetic spectrophotometric determination of trace amounts of iodide in food samples," Analytical Sciences, vol. 26, no. 4, pp. 497-501, 2010.

[20] M. R. Shishehbore and R. Jokar, "A kinetic spectrophotometric method for vanadium(v) determination in food samples using a Janus Green-bromate system," Analytical Methods, vol. 3, no. 12, pp. 2815-2821, 2011.

[21] M. R. Shishehbore, A. Sheibani, and M. Eslami, "Thioinebromate as a new reaction system for kinetic spectrophotometric determination of hydrazine in cooling tower water samples," Journal of Chemistry, vol. 2013, Article ID 861625, 5 pages, 2013.

[22] M. Keyvanfard, K. Alizad, and P. Elahian, "Determination of thiocyanate by kinetic spectrophotometric flow injection analysis," Journal of Chemistry, vol. 2013, Article ID 147364, 5 pages, 2013.

[23] M. R. Shishehbore, A. Sheibani, and E. Mirparizi, "A new kinetic spectrophotometric method for the determination of major metabolite of heroin in biological samples," Chinese Chemical Letters, vol. 23, no. 5, pp. 611-614, 2012.

[24] G. A. Milovanović and L. Stefanović-Ristić, "Kinetic determination of dopamine content in rat brain," Microchemical Journal, vol. 31, no. 3, pp. 293-297, 1985.

[25] L. Bai, W. Zhang, X. Liu, and L. Liang, "Kinetic spectrophotometric determination of vanadium in steels based on the catalytic oxidation of thionine by potassium bromate," Rare Metals, vol. 26, no. 1, pp. 85-88, 2007.

[26] M. J. Bogusz, R.-D. Maier, K.-D. Krüger, and U. Kohls, “Determination of common drugs of abuse in body fluids using one isolation procedure and liquid chromatography-atmosphericpressure chemical- ionization mass spectrometry," Journal of Analytical Toxicology, vol. 22, no. 7, pp. 549-558, 1998.

[27] B. Rezaei and N. Majidi, "A simple and high sensitive spectrophotometric method for ultra trace determination of ruthenium with its catalytic effect on the oxidation of pyronin $B$ by periodate," Spectrochimica Acta A, vol. 66, no. 4-5, pp. 869-873, 2007. 

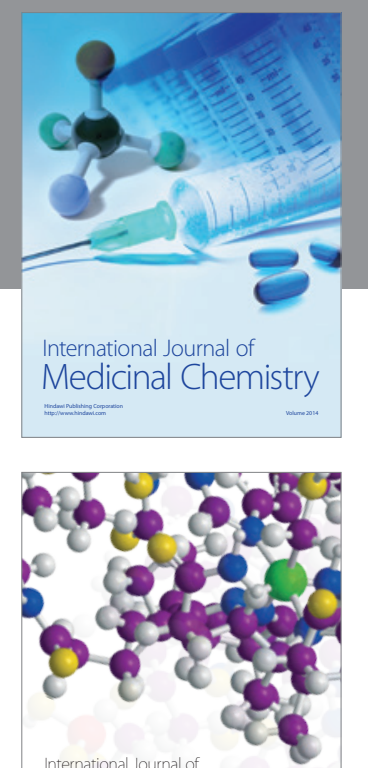

\section{Carbohydrate} Chemistry

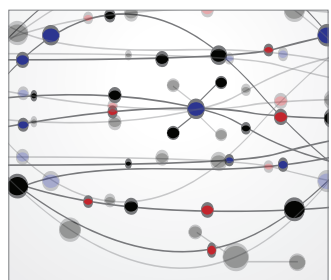

The Scientific World Journal
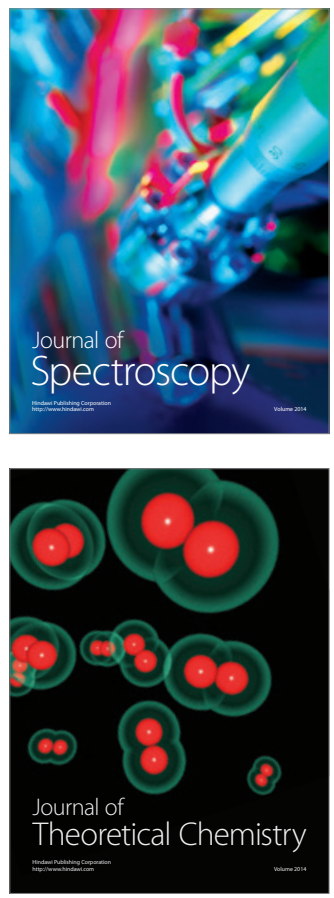
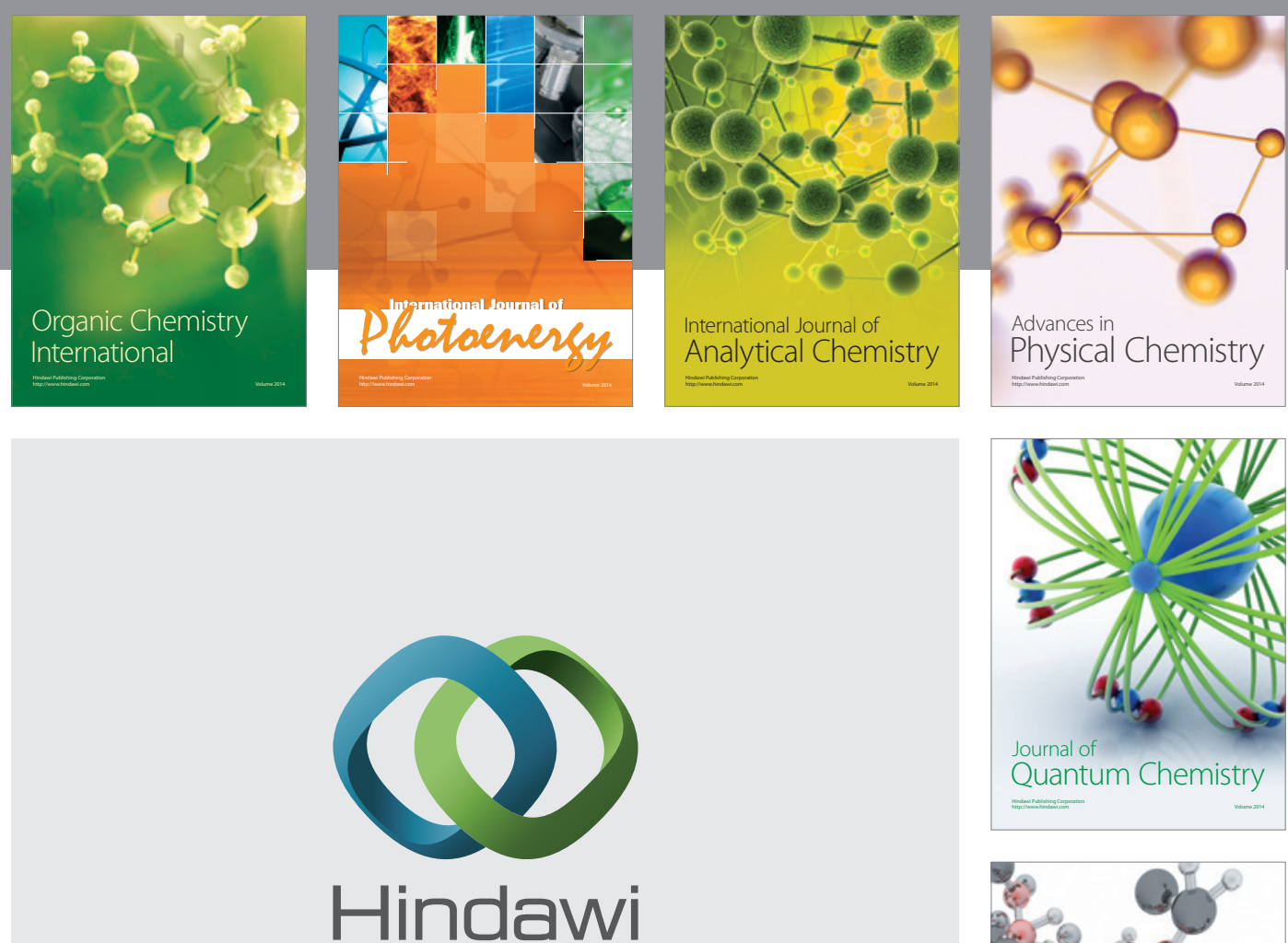

Submit your manuscripts at

http://www.hindawi.com

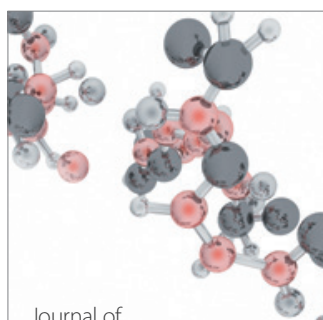

Analytical Methods

in Chemistry

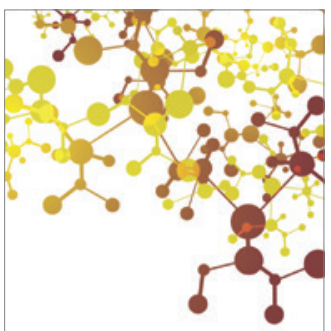

Journal of

Applied Chemistry

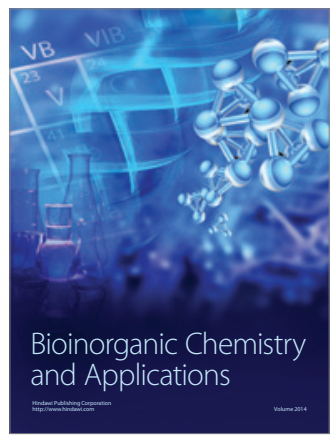

Inorganic Chemistry
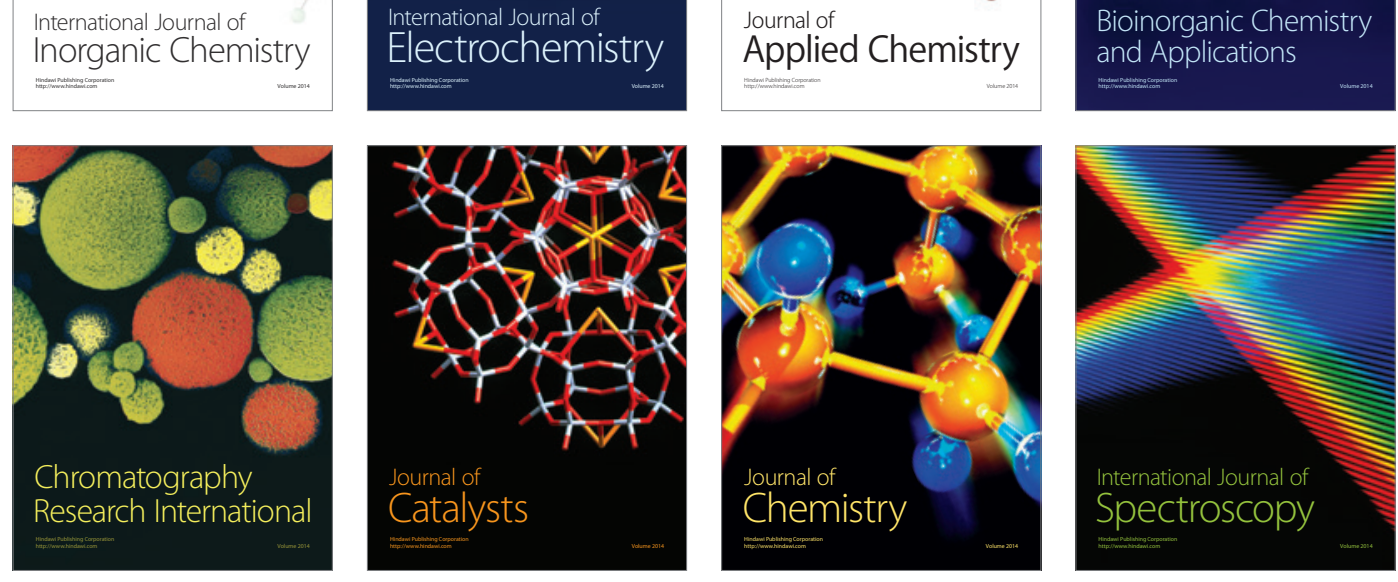